\title{
Investigation of Psychosocial Hazards and Risks of Occupational Physicians Working in Enterprises: A Qualitative Research
}

\author{
Mehmed Zahid ÇÖGENLI ${ }^{\text {iD a }}$ \\ aUsak University, Uşak, Turkey, mzahid.cogenli@usak.edu.tr
}

\begin{tabular}{|c|c|}
\hline ARTICLE INFO & ABSTRACT \\
\hline $\begin{array}{l}\text { Keywords: } \\
\text { Industrial Psychology } \\
\text { Psychosocial Hazard and Risks } \\
\text { Workplace Physician } \\
\text { Enterprises }\end{array}$ & $\begin{array}{l}\text { Purpose - Psychosocial hazard and risks are of importance for work psychology. Psychosocial } \\
\text { hazard is the potential to create psychological, social or physical damage due to the the nature } \\
\text { of the work and the physical factors in the workplace environment. Due to conflict of the } \\
\text { work's requirements with the employee's knowledge, skills and needs and the lack of social } \\
\text { support concerning the work, the work itself and the psychosocial hazards caused by the work } \\
\text { may lead to stress and it is known that they cause serious risks for the employees' health and } \\
\text { safety. The purpose of this study is to assess the psychosocial hazards and risks that } \\
\text { occupational physicians expose to considering occupational health and safety. } \\
\text { Design/Methodology/Approach - A qualitative research method has been used and interview } \\
\text { technique with semi-structured questions has been decided on in the study. In this technique, } \\
\text { the interview protocol, in which questions are mentioned before, is addressed to the } \\
\text { interviewers and the data is collected by recording the answers. In interviews with semi- } \\
\text { structured questions, the researcher can lead the flow of the interview with extra or sub- } \\
\text { questions in accordance with the flow of the interview and can help the interviewers to detail } \\
\text { their answers. } \\
\text { Findings - In this study all of the occupational physicians working in Giresun province was } \\
\text { figured out and they were asked } 10 \text { semi-structured interview questions and the answers were } \\
\text { recorded. Through these questions, the psychosocial hazards and risks that occupational } \\
\text { physicians expose to were tried to be determined. } \\
\text { Discussion - To sum up, it was determined that preventing psychosocial hazards and risks in } \\
\text { workplaces may not only eliminate unproductive work, but also may increase individual and } \\
\text { social life quality as well. Safety culture is one of the most effective instruments in order to } \\
\text { create a healthy and safe working atmosphere and increase the motivation of an individual to } \\
\text { the work. }\end{array}$ \\
\hline
\end{tabular}

\section{Introduction}

Technological developments in developed and developing countries, economic conditions, competative and rushing industrial life may have a negative effect on individuals. Besides the biological, chemical and mechanical and physiological hazards, psychosocial hazards also constitute the occupational risks in working life. Psychosocial hazards are identified by ILO on the basis of business organization and management, occupational satisfaction, the interaction between organizational conditions and the requirements of the work and competence of employees. These interactions are experienced as the resistence of employees to the troubles and serious psychological and physiological effects. Hazards affect individuals via stress.

Psychosocial hazards created by the balance between abilities and physical and mental business demands, technological changes, work-load, pressure by the management, inadequate social support, unsafe working atmosphere and role conflicts cause stress and lead to various risks. Communication problems, exposure to mobbing and stress in working atmosphere and reflection of the problems to the private life are among the problems that are frequently experienced. Correspondingly, unsafe working atmosphere reduces the employees' motivation and occupational performance. Employees are exposed to phycholocial, social and physical problems.

Psychosocial health and safety of employees is one of the important stages of occupational safety. Psychosocial health is ensured when employees feel themselves psychologically and socially healthy and 
safe in working atmosphere. Knowing the psychosocial hazards and risks in working atmosphere, appreciating them accurately and finding necessary solutions are significant in terms of working life and employees. Awareness of these hazards and risks by employees significantly changes their level of influence.

\section{Psychosocial Hazards and Risks in Workplaces}

Psychosocial appreciations about working life became a current issue and the effect of workplace qualifications on health stood out in 1950's. Şahan (2016: 4) expressed the definition of the concept of psychosocial as "it is used in order to explain the effects of social factors on personal qualifications of individuals and it is important for investigating the situations occuring depending on those factors. Establishing healthy workplaces in which employees can do their production activities and also they are appreciated and they can improve themselves is the focus point of work psychology" (Houdmont \& Leka, 2010: 1-31).

Psychosocial health is considered as a component of the concept of health. With the definition of general health by World Health Organization (1946, access date: March, 2019) psychosocial health is expressed as " a complete psychological and social well-being". Psychosocial hazard is defined by International Labour Organization (1998, access date: March, 2019) as " the interaction between occupational satisfaction, business organization and management, environmental and organizational conditions and competence and needs of employees". Psychosocial hazard is considered as the potential of social and environmental conditions that occupational organization and its design are realized for psychological, social or physical damages.

Along with the industrialization as of 19th century social and psychological problems also began to be seen in business life. One of the social consequences of industrialization process is the occurance of various economic classes. Employees are under significant psychological pressure regardless of their status and there exists many factors that may affect the psychology in workplaces negatively. Psychological, cultural or physical situations lead to some changes in employees. Each employee resists to this pressure in different ways and does not experience the same problems. However, a risk occurs in terms of mental health. Besides the chemical, physical and biological risk factors, the factors affecting the health of employees in working life are psychosocial risk factors. Psychosocial risk factors are considered as the factors which lead to employees to experience potential psychological health problems (Korkut, 2014: 3-5).

According to Özağaç (2013: 14-15), the work itself and the psychosocial hazards of the work begin to affect the health and generate psychosocial risks when the requirements of the work conflict with the knowledge, skills and abilities of employees and the social support about the work is insufficient. The existence of close relationship between the mental state and health of individuals has important risks in business life. (Buyens et al., 2009: 103). According to Leka and Cox (2008: 1), psychosocial risks are psychological and physical damages caused by administrational practices in business life and occuring as a result of organizational and social problems.

The increase in non-standard and flexible working hours in business life and the aging of the working population reveal many risks and hazards. In addition, the situations such as unbalanced distribution of workload, managers' lack of interest about problems, employees' fear of losing job, working hours, shift system, night shifts, working overtime, ergonomic conditions become an important source of mental problems and cause work accidents (Richards, 2003: 20-22). The conditions determining the psychosocial hazards are categorized according to the conditions and environment of the work as the following:

-Organizational culture; lack of communication, troubles in problem-solving, ambiguity in organizational goals.

-Organizational role; role ambiguity, conflict and inadequacy and over-loaded task.

-Career development; career development ambiguity, excessive status attribution, uninsured employment and insufficient social value for the job.

-Freedom for decision; insufficient participation in decision-making process, lack of supervision about the work.

-Lack of interpersonal communication at work; interpersonal conflicts, violence and lack of social support. 
-Work and home conflict; conflict of expectations, insufficient support at home, career conflict.

AISGA (2007: 1681) defines psychosocial risks as "new and gradually increasing risks of occupational health and safety." The criteria that should be considered while evaluating the psychosocial risks are:

-The number of people exposed to hazards

-The frequency of exposure to hazard

-Time period of exposure to hazard

-Knowledge/educational level about the hazard

-The frequency of control and recovery

-Working conditions

Psychosocial risks that can be encountered in workplaces can be listed as (Vatansever, 2014: 126):

-Monotony at work

-Technological changes

-Hazardous factors at work, working atmosphere and environmental conditions

-Excessive workload, evaluation and promotion mechanisms

-The fear of losing job

-Ambiguities in roles

-Interpersonal relations

-Sense of responsibility

-No participation by management and competition

-Violation of psychological contract

-Aging labour force

-Stress

-Intimidation

Optimum analysis of the criteria considered during the appreciation of the psychosocial risks enables us to determine the factors of psychosocial risks accurately. Accurate analysis of the risks leads to find accurate solutions for these risks. The work including hazard, inappropriate environmental conditions, employees' exposure to mobbing and unconcerned management to the problems of employees cause serious problems.

Psychosocial hazards and risks are stated as direct stress factors such as the content and nature of the work, workload and pace, working hours, organizational climate and culture, interpersonal relations, role conflicts, role ambiguity, career improvement, lack of job insurance and business-private life balance which has gradually become important in recent years. When we analyze the health problems caused by psychosocial risks, we can see that the employees affected by the stress at work feel themselves nervous, aggressive, tired and unhappy and are not able concentrate and make decisions and are not satisfied with the job. These situations may lead to some problems such as heart diseases, digestion system disorders, headaches, musculoskeletal system problems. It was determined that especially stress at work leads to coronary heart diseases.

It is stated that the situations such as decrease in interest in workplaces due to the work stress, increase in non-attendance to work, decrease in efficiency and performance, increase in work accidents due to unsafe working environment, decrease in customer satisfaction and the damage in the image of enterprises on the eyes of the employees and environment are the administrative problems caused by psychosocial risks (Eğin, 2015: 33-44). 
The concepts that should be discussed while analyzing the psychological violence in workplaces are mobbing and stress. Mobbing and stress are used in order to define the problems and hazards in workplaces. Because stress and mobbing are factors which affect the psychological and physical health of employees in workplaces and cause distrust of employees to their organizations and themselves. The importance of safety culture emerges with these concepts. Safety culture is expressed as beliefs, thoughts and opinions which minimize the hazards and risks by affecting the behaviours of managers and employees at work.

\section{Mobbing}

Psychosocial hazard and risk factors have gradually become important in our country and in the world. The factors such as hierarchical structure of the organization, knowlegde and experience levels of employees, businesses and activities in workplaces, work accidents and occupational disease registries are the determiners in defining psychosocial hazards.

"Mobbing is the body of vicious, deliberate and negative attitudes and behaviours in workplaces by one or more than one person towards other person or people which goes on systematically for a period of time and aims to intimidate, pasify and detract from work and damages the personalities, professional status, social relations and health of a victim or victims" (ÇSGB, 2013: 10).

Dr. Heinz Leymann is the person who related the concept of psychological abuse (mobbing) with business life. Leymann (1990: 119) defined mobbing as "a kind of psychological terror which happens by directing a systematic, hostile and unethical communication to a person by another one or ones". For the negative behaviours to be called as mobbing, there should be aggressive and destructive aim, these behaviours should be repeated, frequent and continuous and there should be a power imbalance between people. Mobbing is one the most important psychosocial risk factors in business life. Authoritarian organizational structure in institutions usually brings about psychological abuse and in long term it may become one of the part of administrative practices (Davenport, Schwartz \& Elliott, 2003: 20-23). Based on the definitions in the literature and the important points mentioned above, the definition of mobbing can be framed as follows: "Mobbing is the set of malevolent behaviors exhibited systematically, consciously, and continuously with the intention of humiliating a person or persons and forcing them to leave the workplace" (Çögenli, Asunakutlu \& Türegün, 2017: 111). The ambiguities in organizations forms a basis for mobbing.

Mobbing that people are exposed to in workplaces should include some factors (ÇSGB, 2013: 10):

-should happen in workplaces.

-should be continuous and repeated frequently.

-should be systematical.

-should be performed deliberately.

-should be aggressive and aim to pasify.

-should have harmful effects on personality, health or business life of the mobbed employees.

Environmental factors and personalities of parties are considered as the reason why psychological terror happens in workplaces. In addition, distruptions in organization may occur due to organizational factors in workplaces and management-originated reasons. For instance, the situations such as role conflicts heavy workload, nervous and stressful atmosphere, low job satisfaction, annoyance from leadership style cause distruptions. There are many options about the personality of parties in conducted studies. The victim is not a reason for the mobbing, but the personality of the employee distrupts as a result of mobbing (Archer, 1999: 94-105). These causes include personal reasons (i.e. reasons stemming from the mobber or victim), organizational reasons, and sociocultural reasons (Leymann 1996; Leymann and Gustafsson, 1996; Davenport et al., 2003; Zapf, 1999; Chappell and Di Martino, 2000; Einarsen, 1999).

Personal Reasons: Mobbing may start with a dispute and occur as a continuation of this behavior. The mobber may include management or colleagues in this event.

Organizational Reasons: Hierarchical organizational structure in workplaces forms a basis for psychological terror. This structure becomes a suitable environment for the mobbers to hide themselves. Bad management, communicational problems, poor leadership, fear of losing job in competative atmosphere, failure to fulfill 
the expected works, a different structuring and the continuous repetation of same events cause psychological abuse (Yllmaz \& Kaymaz, 2014: 75).

Socioculturel Reasons: Lack of self-confidence, alienation, increasing immigration and kinship relations create a field that supports mobbing. When socially analyzed, the perception of destroying the weaker by the stronger, the destruction of the common working culture and using the changes against the employees are among the social reasons for mobbing (Greenhaus \& Beutell, 1985: 77-80).

Bad management, stressful working environment, poor leadership, conflicts in management, failure of employees to fulfill the expected works, less or no team work, excessive hierarchical structure, fear of losing job in case of competition, no new ideas, continuous repetition, monotony and highly stressful working environment are indicated as the reasons for psychological abuse in workplaces. Ignorance of the presence of psychological abuse in workplaces by managers leads this situation to last. The consequences of mobbing should be discussed concerning the individuals, organizations and society. The victim who is affected and damaged from mobbing most is exposed to mental, physical and economical effects. The employee who is considered as a hard case can also be isolated from social life. The consequences in terms of organization and society may cause decrease in work inefficiency and decrease in trust and prestige in workplace along with mobbing (Tinaz, 2006: 25-27).

\section{Stress}

Stress comes from the Latin word of 'estrictia'. While it was used in 17th century in the meanings of worry, pain, sorrow and evil, it began to be used in 18th and 19th centuries in the meanings of power and pressure for people, objects and mental structure. We can see it to in all fields of our lives and it is regarded as a sign of discomfort today (Güçlü, 2001: 92).

Stress is regarded as the disease of the age today. Stress in workplaces is very important for daily life because it is a frequently observed situation in daily life and working period is a very long period in human life. In European Commission stress in workplaces is defined as "sensual, cognitive, behavioural and physical reaction of employees to business organization, its environment and its harmful aspects to avoid". One of the definitions of stress is that "as a result of the effects of environmental and working conditions, individual's intellectual and physical action in order to adapt to the related situations by creating special biochemical secretion on body". It is stated that stress is one the most commonly observed psychosocial risks and stress in workplaces is associated with the problems such as abuse and tyranny (Gök, 2009: 430-435).

Beehr and Newman (1984: 58) defined the work stress as " a situation which is determined by the changes that forces individuals to differ for usual functions and derives from their interaction with other people". Also work stress can be defined as " the lack of harmony due to both the nature of work and the personality of a person and the reaction of him or her for it" (Şenyiğit, 2004: 103). The reason why strees is very important today is its effect on employees' health and the efficiency of the work. Work stress is a situation that must be solved by individuals and organizations. The reason why there is a topic that should be paid attention for all occupation groups is that it can be encountered in all occupations. The reactions may vary in each occupation group (Rantanen, 1999: 478-479).

Reasons of work stress are discussed under two titles as individual and organizational. Individual reasons are indicated as the factors such as emotional and biological structure, family problems, living standards and habits, economic conditions, middle and advanced age crises of an individual. Policies of the management or organization, excessive workload, limited time, distrust to political atmosphere, frustration, worries due to responsibilities, lack of harmony between organization and the values of employees are among the organizational reasons (Güçlü, 2001: 96-100).

The situations such as job dissatisfaction, promotion, retirement, appointment, unemployment, over work, exhaustion, authoritarian management, occupational problems of women, technological stress, job insurance and safety may cause the stress about business order. Social and mental stress resources are indicated as feeling empty, feeling of guilt, role conflict, low wages, age, gender, family life, solitude, socio-economical conditions, career ambiguity, losing the feeling of tolerance and failure to make communication. Physical stress resources are the factors such as noise, thermal comfort conditions, pressure and silence. According to Braham (1998: 52-54), signs of stress are grouped as physical, mental, emotional and social. 
According to the conducted studies, it has been determined that environmental conditions generally lead to stress and the stress factor remains stable as long as the environment does not change and it goes on increasingly. However, stress becomes a stress resource for other employees in environment if it derives from the personality of the employee. Environmental factors are important in the incidence of stress. Accordingly, stress resources may change depending on environmental factors. Noise, lack of thermal comfort conditions, temperature, crowded working environment, dust and radiation can be expressed as examples for stress reasons caused by physical environment. Heavy and tiring works, working under the pressure of time, career ambiguity and interpersonal communication are expressed as the examples of the problems about the work. Stress resources affect the health of employees either individual or social (Eğin, 2015: 8-9).

According to Türetgen et al. (2012: 147-153 narrated by Vatansever, 2014: 122) work stress has five main factors.

\section{-Organizational norms and practices \\ -Work and workload \\ -Non-trust based interpersonal relations \\ -Work with no improvement opportunities}

-Physical properties of working environment

\section{Safety Culture}

Culture is a concept with broad meanings. Culture is " the way of thoughts, feelings and behaviours presenting the original patterns of human groups and expressed by created and transferred symbols". With the continuous development in science the concept of culture also changes and gain new meanings. It is stated as the body of behaviours which expresses a life style as the consequence of living in the same society (Alakuş, 2004: 62-65).

Safety is a concept which is frequently used in every fields of daily life and comes after the need to live in Maslow's hierarchy of need theory. Following the basic needs, an individual needs to safe himself or herself. In order to ensure a safe environment in an enterprise, a culture should be established (Ültanır, 2003: 291).

The concept of safety culture was firstly mentioned in 1987 in a report prepared by OECD Nuclear Agency following the nuclear accident in Chernobyl. After long researches and studies, it was concluded that safety culture became a key for preventing work accidents and establishing a safe working environment (Cox \& Flin, 1998: 190)

According to Cox and Cheyne (2000: 114-115) safety culture reflects attitudes, values and beliefs which determine the efficiency of an organization in terms of health and safety and are shared by employees. Safety culture is to make a habit of healthy and safe behaviours. Enterprises have their own safety culture. A management understanding which is open to participation and communication and emphasizes health and safety and takes preventive measures is an important factor for the development of safety culture. Safety culture focuses on the participation of the all people in organization. It affects the behaviours of all employees at work in the organization. It has a resistant and strong structure against changes (Wolinska \& Rakowska, 2014: 1089-1093).

The factors causing work accidents are the work itself, employees and organizations. Safety culture is one of the important issues to be discussed in preventing work accidents and establishing safe working environment. Perspective of enterprise managements to safety culture and fulfilling their responsibilities are one of the important steps in establishing safety culture in workplaces.

The purposes of safety culture can be outlines as follows (Uslu, 2014: 38-39):

-Providing the safety about important issues

-Providing the commitment of employees to safety through interest and participation

-Establishing behavioural norms by sharing the opinions about risks, accidents and diseases 
-Deciding the efficiency of the health and safety programme of the enterprise

The policies for providing flexible working hours, permissions and the balance between business and private life are followed in order to establish safety culture in organizations. In addition, communication in management organizations is important for sharing information, facilitating works and solving the problems and conflicts. An effective communication becomes necessary in order to reach administrative targets and increase the efficiency (Hofstede, 2011: 21-22).

It is stated that education is one of the important factors in establishing organizational culture. Healthy behaviours of employees also affect the development process of knowledge, skills and abilities. It is necessary to minimize the psychosocial risk factors and provide a healthy working environment by raising awareness of employees through a planned education system. The purpose of a good safety culture is to protect employees and prevent their unsafe behaviours and have them recognize the hazards and risks. Although to what extent safety culture will be handled and the performance criteria will be appreciated are not indicated exactly, they differ according to countries and sectors. However, universally accepted safety dimensions are handled as organizational commitment, participation by the management, authorization of employees, reward system and reporting system (Yumuşak, 2008: 241-247).

\section{Methodology \\ Purpose of Study}

There are many risk factors affecting human health in business life. Psychosocial risk factors are the factors deriving from the situations such as working conditions, requirements of the work, work environment and technological developments and causing psychological, physical and social damages on individuals. Detecting and appreciating the hazards and risks that employees expose to in terms of business health are of importance. The purpose of this study is to detect and appreciate the psychosocial hazards and risks that occupational physicians working in Giresun province expose to.

\section{Method of the Study}

This research is designed with a qualitative research method. Qualitative researches deal with the process rather than the products or outputs. Semi-structured interview technique is frequently preferred by researchers because it is flexible at a certain level and eliminates the limitations in tests and questionnaires and helps to obtain detailed information on determined subject. Semi-structured interviews are neither rigid nor flexible compared to other types of interviews (Yıldırım \& Şimşek, 2005: 366). Semi-structured interview technique was used in this research because it is between the two. Interview questions were prepared by paying attention to be understood easily and not to guide the interviewer.

This study includes all occupational physicians working in Giresun province. Occupational Health and Safety Registration, Follow and Monitoring Program (ISG-Katip) was used to determine the number of workplace physicians working in this province and the workplaces they work in. In this way, it has been determined that there are 5 doctors working as occupational physicians in Giresun province. As a result, all occupational physicians working in Giresun were reached. Before the interview, the purpose of the research was briefly explained to the physicians and the importance of the accuracy of the answers was emphasized. Through these questions it was aimed to determine the psychosocial hazards and risks that occupational physicians expose to.

\section{Findings and Analysis}

The interviews are based on the principle of secrecy and the names of participant physicians are not explained. Male interviewers were coded "EG1, EG2, EG3, ..." as and female interviewer is coded as "KG, KG1, KG2, ...". Audio recordings were transferred to computer.

The interview with occupational physicians was analyzed under 3 main themes: They were determined as:

a)Reasons of Psychosocial factors

b)Consequences of Psychosocial factors

c)Solution recommendations for Psychosocial problems 
The reasons of the Psychosocial factors that the occupational physicians expose to were analyzed in five subcategories as non-institutional workplaces, late payment of wages, long working hours, education levels and management-related problems. The sub-category of psychological and social consequences is under the theme of the consequences of Psychosocial factors.

\section{Reasons of Psychosocial Factors That Occupational Physicians Expose to}

There are some reasons which affect the health of employees in workplaces and form the psychosocial factors. Reasons of psychosocial factors that occupational physicians expose to were tried to be determined via the major question of "Have you ever experienced one or some of the factors affecting your psychosocial health?". Reasons of the factors affecting the occupational physicians in psychosocial way were seperately analyzed under five categories.

\section{- Non-institutional Workplaces}

It was determined in the conducted study that 2 out of 5 occupational physicians stated the problems due to the fact that the workplace was not institutional and private sector. The occupational physicians think that problems are not solved because the workplace is not private sector. The reference statements obtained from the interview results are as the following;

"I do not think that I experience much, but we have some problems about the working environment and wages such as late payment because we are not institutional". EG1

"There are also different problems of being a private sector". EG2

These statements show that the problems in workplace can not be solved because of the non-institutional structure. It has been determined that there are problems in the workplace with private sector structure about solving communication and management related situations and this creates psychosocial hazards and risks on occupational physicians.

\section{- Late Payment of Wages}

It was determined that wage problems were one of the reasons for occupational physicians' exposure to Psychosocial hazards and risks. 2 of the interviewed physicians indicated that they exposed to Psychosocial factors because wages were not paid on time. Reference statements are;

"...about the wages such as late payment. We have problems about wages and stress depending on it" EG1

It is a risk factor when the wages regarded as the reward of labour by employees are not paid on time. As mentioned above, this situation causes problems and stress on occupational physicians.

"When we have problems about wages, my private life is also affected financially." ".....wages should be suitable for employees".

Late payment of wages and low payment in amount for individuals are problems. In addition, it is known that low wages have negative effects in terms of job satisfaction.

\section{- Long Working Hours}

3 out of 5 interviewed occupational physicians answered to the question that long working hours was the psychosocial factor that they expose to. Reference statements are;

"The reasons for stress in workplaces are usually related with time. It is about the working environment. We sometimes have to work in hours that we do not want to. We have to work out of working hours". EG1

"We spend most of our times in workplaces. This may take long hours. Insufficient ergononic conditions in working environment is also another problem". EG1

As a result of the interview, occupational physicians states that ergonomic problems also occur due to long working hours. This situation determined as a different problem is a hazard and risk for occupational physicians.

"Employers want the educations and examinations to be organized out of the working hours. We work for long hours and we usually work out of the working hours". EG2 
"We can work for long hours. We also have to work on Saturdays. If Saturdays and Sundays were the off days for us, it would be better for us to spare some time for our family". EG4

In this mentioned statement it was determined by occupational physicians that working at weekends was a reason for the exposure to psychosocial factors. We can see that extension of working hours is considered as hazard and risk by the physicians.

\section{- Educational Level}

Low educational level of the people that physicians work on is another psychosocial hazard factor for work. As a result of the study it was determined that occupational physicians were affected by the low educational level. The reference statements are as follows;

"Educational level of the people that we work on is very low. I sometimes may have problems in communication with people during the examinations.....Low educational level of the employees is also problem...lack of occupational health and safety culture is also another problem". EG2

"We have to analyze the society for psychological health. Therefore, education is very important. I work with the people with low educational level and experience some problems". KG5

It was indicated in another statement of physician that education was very important in order to establish psychosocial health. Here, there comes out the importance of education.

\section{- Administritive Problems}

\section{Communication Problems With Administration and Colleagues:}

A properly operating organizational and hierarchical structure in workplaces is important in terms of psychosocial health of employees. When the problems of occupational physicians with the administration and colleagues are observed, the reference statements are;

"We have a good working environment with our colleagues here. In this aspect, I'm pleased and happy". EG2

The statement above states that this physician have no problem with his colleagues. A good working environment satisfies the workplace physician.

"We absolutely have problems with our work but we rather have conflicts with managers. This causes a tense working environment. We even expose to favouritism. Some of them comes to work, some does not. This, of course, makes the working environment stressful and unhappy. When we inform the administration about this situation, we do not have any answer".EG4

"When I have a problem with the employers in workplaces that I go for a check up, my employer tries to drop the subject without doing anything because he/she thinks that he/she will earn money. Working long hours or in heavy conditions is not important for employers. This is a problem". EG4

"Meetings should be held as the whole team in order to talk about the problems and troubles in workplaces. We demand it in workplaces. We have meetings but how much efficient they are is debatable". EG4

Including the administration to the problems in workplaces is hazardous for employees. The fact that administration is involved in the reasons of the problem instead of solving the problem becomes a Psychosocial hazard for occupational physicians. Not fulfilling the meeting demands for the solution of the problems in workplaces or infertile meetings are indicated in statement of the physician as the reason for the increase in problem.

\section{Failure to Apply Sanctions:}

"I can say that I do not feel well in workplace. Because the sanction are not applied".EG3

It is stated in the statement of the physician that the fact that sanctions are not applied causes the physician to feel bad. When the promises by the managers are not kept, distrust occurs in employees and it affects the employees negatively. 


\section{Financial Problems:}

When the wages are not paid by the administration on time, financial problems occur in terms of occupational physicians. These problems are stated as the reason for exposure to psychosocial factors in the statement of workplace physician. Besides the financial problems have negative effects on occupational physicians, they increase the possibility of performance decrease at work.

"Of course, experiencing financial problems is a problem, it reflects to our work". EG2

\section{Consequences of Psychosocial Factors that Occupational physicians Expose to}

Consequences of psychosocial hazards and risks that occupational physicians expose to were analyzed in previously determined sub-categories. Psychological and social consequences of the psychosocial factors were determined in accordance with the answers to the questions asked to the occupational physicians.

\section{- Psychological Consequences}

As a result of the occupational physicians' exposure to psychosocial factors, psychological effects were also analyzed. The stress factors that the occupational physicians experience, stress-causing situations and psychological effects in workplaces were evaluated using the following statements.

"The reason for stress during the work is generally related with time. It is about working environment". EG1

"In the places with no mutual respect I feel bad and it makes me unhappy. I can say that this is my essential source of stress". EG2

"Stress happens as in every person's life. There are the factors that create stress, of course. It is my biggest source of stress that the working people do not obey the rules and do not fulfill their responsibilities. I deal with lots of people. Unfortunately, everything cannot work as it has to be". EG3

It was determined that being together with many people due to the field of the work; however, not obeying the rules or not fulfilling the obligations were sources of stress in the occupational physicians. It was observed in physician's statement that the presence of stress creating factors were recognized.

"Stress has become a part of our work. We deal with lots of people". "Everything affects me here. We try to cope with this stress in the rest of time. Shortly, negative in all".EG4

"In some cases you keep your silence. Because the person in front of you is dull. This creates a psychological trauma, of course". "Everything may become a stress resource in my business life". KG5

Another negative situation was the psychological trauma effect as a result of communication problems with the person in front of the occupational physician. It is seen that poor working conditions and failure to find a solution has become a source of stress in terms of occupational physician.

\section{Psychosocial Health According to Occupational Physicians:}

5 occupational physicians were asked how they defined the psychosocial health. When the answers were analyzed, it was determined how occupational physicians defined the psychosocial health and to what extend it affected their works. The determined reference statements are;

"I can define it as the mental and psychological well-being of working people. That's what is for my profession. It's important to have a complete well-being while working".EG1

"I define it as the complete psychological well-being in business life".EG2

"Psychological health in busines and social life".EG3

"Working hours, environment, wages must comply with the employees. If you have a happy environment at work, you will be happy and comfortable. I can say that psychosocial health is to provide these situations".EG4

In the statements above the physician points out the working environment, wages and working hours and states that good conditions make the employees happy and therefore a good environment occurs psychosocially. 
"We have to analyze the society to ensure Psychosocial health. Therefore, education is important. We always talk about rights and justice, but we ignore that other people have some rights. This affects the society psychosocially. It also affects us".KG5

This occupational physician who works together with many people in her working environment emphasizes education and expresses that Psychosocial health status reflects to them.

\section{- Social Consequences}

Another situation which occurs as a result of the exposure to psychosocial hazards and risks is analyzed as social consequences. The balance between family and private life of occupational physicians, the events experienced with patients and employees in workplaces were discussed as the consequences of the exposure which socially affect occupational physicians.

\section{The Balance Between Family and Business Life:}

The situations such as long working hours, late payment of wages and the problems with administration and colleagues also affect the family and private life of employees according to the interview results. 4 out of 5 interviewed occupational physicians state that the problems in business life reflect to private life. Reference statements are as follows:

"I have to spend less time with my family".EG1

"Going home late and working log hours inevitably affect my family order. Fatigue and tension at the end of the day also reflect to home or unhappy events in the workplace also reflect to home". EG2

The occupational physicians stated in their statements that the problems in working environment affected their family order and they had to spare less time for their families. They also expressed that the tension in the workplace also reflected to home. In addition, it was stated that long working hours damaged the balance between family and business life.

"I leave the problem at work. Therefore, they do not affect my private life negatively". EG3

The resistence to psychosocial factors by each employee is different. The physician with the statement above says that he leaves the problems in the workplace and he does not reflect them to his family and private life.

"When I experience problems in wages, my private life is affected financially. I can say that my business life partially reflects to my private life. When I'm highly overwhelmed at work, my unhappiness and tension reflect to the family order. Of course, this is not a continuous and ongoing situation. I reflect if I'm really overwhelmed". EG4

"I take lots of work to home. Our family and private life rather depends on work. If the business goes well, family life goes well. You don't have much time for yourself".KG5

It was determined that wage problems in workplace affected the family and private life of occupational physicians financially. It was also determined that good or bad events in businees life reflected to family life and occupational physicians could not spend enough time for themselves and families.

\section{Situations Experienced With Patients:}

Occupational physicians are together with many patients in their workplaces. The situations such as the problems with patients and employees and communication problems occur. Low educational level of the people worked on also is a problem for occupational physicians. Especially communication problems attracts attention in conducted interviews.

"Educational level of the people we work on is low. I may have problems in communication with people while expressing something during examination".EG2

The physicians stated with this statement that the communication problems that he experienced with the employees during the examination affected him. 1 out of 5 the physicians mentions about the situations with patients. 


\section{Psychosocial Solution Recommendations}

The reasons and consequences of the psychosocial hazards and risks that occupational physicians expose to were analyzed according to the answers of the occupational physicians. Coping skills of occupational physicians with these hazards and risks and solution recommendatios were tried to be determined through the questions. The responses and resistence to the problems and coping methods of each employee vary. While some of the employees overcomes this process easily, the resistence and psychosocial influence level of some of the employees is more. 3 of the occupational physicians state that problems would be solved through communication. They state that the expansion of education and the existence of a systematic order may be the solution.

"I'm trying to solve my problems. I'm trying to overcome my stress-creating problems through communication". "We sometimes have problems. However, I'm trying to have direct communication with the addressee. I did not have so many problems".EG1

Expressing the problem and trying to communicate with the person are suggested as a solution method. In this statement the physician states that he does not have so many problems and the problems can be solved through communication.

"I usually try not to get in touch with bad characters. I contact the administration when I encounter an undesirable situation. I report the problems". "Levels of education should be increased starting from the furthest points, and moral, good manners and especially respect should be imposed. Education is very important. Employees need to be conscious. In this way, psychological health can be established. The sense of stress can be reduced".EG2

"I try to keep calm. I try to talk to the person in front of me". EG2

It was suggested that another solution method is to report to administration. Solving the problems depends on the attitudes of administration. The physician mentioned about the importance of education and stated that raising the awareness of employees was important psychologically. Awareness of employees about the hazards and risks and determining the solution methods are the issues to be paid attention in terms of employee health.

"If I can not solve myself, I will talk to the managers. In addition, seminars should be organized to draw attention to psychosocial problems. Psychological counseling should be established. I think it should be systematical and should be established in all institutions".EG3

"I do not have too much lack of communication. If I experience, I try to solve it. I think of how to figure it out". EG3

In the statement above the physician stated that seminars should be organized and psychosocial issues should be emphasized. He stated that consultancy should be established in every institution and a system should be established in order to solve the problems of employees.

"Some of them are solved, but some of them can not be solved. Actually, everthing can be solved. There should be a certain system and order". EG4

The fact that some of the problems are solved but some of them are not affect the physician. However, it was stated that this can be figured out through a certain system and order.

"People should be educated and informed. Education should be tough and centripetal. Ordinary education will not be a solution. Its content should be enriched. When people are educated, education should improve the family members. However, we do not manage it. If the next generation does not improve, this is not education. This is our problem". KG5

"The best way to cope with stress is to do the work best and you should not care anything too much. A person should remind and feel himself/herself that he/she is more valuable than anaything. Work is not everthing. If you feel that you are valuable, you can cope with stress then". "We have communication problem. I usually solve it by silence. Otherwise, you cannot solve it. Because when you address it, it turns into a fight. I think silence is the most accurate and natural way".KG5

The importance of education and the need to raise awareness in individuals are mentioned in the statements above. Employees are not usually aware of the problem they experience in workplace or think that they are 
temporary. However, the extension of this situation causes the problems to grow and affect employees psychologically. Lack of communication and wrong attitude by the administration make this situation worse.

\section{Conclusions and Recommendations}

The data obtained as a result of the study conducted to investigate the psychosocial hazards and risks that occupational physicians expose to were analyzed. The results from the research are presented in this chapter.

\section{Consequences of the reasons of exposure to psychosocial factors}

There are psychosocial hazard and risk factors to affect an individual in workplaces. It is important that employees know the exposure reasons and are aware of this situation. One of the reasons that interviewed occupational physicians think as the cause of exposure is that the workplace is not institutional. It was stated in the statements of EG1 and EG2 that working in private sector caused some problems and this complicated the situation. It was determined that this was considered by occupational physicians as a problem.

Late payment of wages and long working hours seem to be psychosocial hazard and risk factors on employees. It was observed in the conducted research that occupational physicians were affected from this situation. Insufficient job satisfaction and no remuneration on time cause negative effects on occupational physicians. At the same time, this situation causes employees to have financial problems and feel bad. The interviewer called as EG1 states this situation reflects him as stress. In addition, the interviewers called as EG2 and EG4 mentioned about the reflections of this situation to their family and private life. Late payment of wages affect both private and business life of occupational physicians. It causes the efficiency of employees in workplace to decrease and to have stress.

For the employees who spend most of their time in the workplace the extension of working hours and working overtime are separate hazards and risks. Occupational physicians state in their statements that employers' desire for examination hours following the working hours is a source of stress in terms of occupational physicians. They also indicate that this affects their family life. It is stated that another hazard is ergonomic conditions for the occupational physicians who spend most of their times in workplaces. EG1 said that he was ergonomically disturbed by the extension of working hours.

Another situation including psychosocial hazards and risks is the lack of communication with the administration. Occupational physicians state that the solutions for the problems by the administration are not sufficient. As the meetings and interviews are inefficient, psychosocial risks still exist in terms of occupational physicians.

Mobbing, called also as psychological violence, is a situation in which employees are psychologically and socially in danger. Administration or colleagues have tiresome and intimidating behaviours on employees. At that point, there is a significant hazard for occupational physicians. In the research 4 of the physicians do not think to be exposed to mobbing; however, 1 of them thinks to be exposed to. The occupational physicians who thinks to be exposed to mobbing is female; the occupational physicians who do not think to be exposed to mobbing are males. Here, gender attracts attention in exposure to mobbing. 2 of the occupational physicians state that they will not let mobbing happen. Mobbing by colleagues and inclusion by administration following mobbing lead to undesirable consequences. EG4 in the interview stated that he exposed to mobbing, but the adminisration did not find a solution for it and kept silent.

Communication problem is another important psychosocial hazard and risk for employees. Occupational physicians state that the communication problem that they have with patients, colleagues and administration is important.

\section{Consequences of exposure to psychosocial hazards and risks}

Employees are affected from most of negative situations that they experience in working environment. Psychological and social consequences of these negative situations were analyzed in terms of occupational physicians. These negative situations result as stress in occupational physicians. It was determined in conducted study that working hours led to stress in occupational physicians. The interviewer called as EG2 stated that he felt unhappy and nervous when people lost respect to each other and this was a source of 
stress for occupational physicians. They stated that they experienced psychological depression and they felt unhappy when they had communication problems and they could not express themselves. As a result of the interview, EG4 stated that whne he had a communication problem and could not express himself, this had a traumatic effect on him.

There are also social consequences of psychosocial hazards and risks to be exposed to. Negative experiences of occupational physicians in workplaces affect both social and family life of individuals. EG1 stated that spending less time with family was a difficult situation for both his family and himself. Results of the study indicate that the problems in working environment lead to occupational physicians to be alone in social life, to withdraw and not to allow time for themeselves and undesirable situations occur.

Educating employees against psychosocial hazards and risks is important. There should be institutions in workplaces where employees can benefit and recieve consultancy. Employees should be given a job distribution according to their knowledge and skills, and the roles in the workplace should be clear. Sufficient social support for employees should be ensured. In order to protect the employees from the effects of stress, knowing the diet, exercise and relaxation techniques by the employees is a step to protect their health.

As a conclusion, psychosocial risks in working environment are inevitable and they endanger the health and safety of employees. Sharing the problems in workplaces with administration and determining fair solution ways are significant. An environment of trust in every aspects should be created in workplaces and employees should feel themselves psychologically strong and roles should be determined clearly. It was determined that preventing psychosocial hazards and risks not only eliminate inefficient work but also increase the quality of individual and social life as well. One of the most efficient instruments to create healthy and safe working environments and increase the motivation of employees to the work is safety culture. Creating an understanding of positive safety culture and educating employees to be psychologically and physically conscious are significant steps in order to prevent psychosocial hazards and risks.

\section{References}

AISGA. (2007). Psychosocial Risks in Occupational Health and Safety. ISG Bulletin. 74/TR, 1681.

Alakuş, A. O. (2004). An Analysis of Cultural Concept Definitions. National Education Journal, 62-65.

Archer, D. (1999). "Exploring "bullying" culture in the paramilitary organisation". International Journal of Manpower, 94-105.

Braham, B. J. (1998). Staying Under Fire, Stress management. (V. G. Diker, Trans.) Istanbul: Hayat. 52-54.

Buyens, D., Dijk, H. V., Dewilde, T., Vos, A. d. (2009). The ageing Workforce: Perceptions of Career Ending. Journal of Managerial Psychology, 103.

Chappell, D., Di Martino, V. (1999). Violence at Work. Asian-Pacific Newsletter on Occupational Health and Safety, 6 (1).

Cox, S., Cheyne, A. (2000). Assessing Safety Culture in Offshore Environments. Safety Science, 34, 114-115.

Cox, S., Flin, R. (1998). Safety Culture: Philosopher's Stone or Man of Straw? Work and Stress, 190.

Çögenli, M. Z., Asunakutlu, T., \& Türegün, Z. N. (2017). Gender and Mobbing: The Case of Turkey. Journal of Business Research Turk, 109-121.

Çöl, S. Ö. (2008). Psychological Violence in the Workplace: A Research on Hospital Workers. Work and Society, 107-112.

ÇSGB. (2013). Psychological Abuse at Workplaces (Mobbing), Information Guide, 10. Ankara: Ministry of Labor and Social Security, General Directorate of Labor.

Davenport, N., Schwartz, R. D., \& Elliott, G. P. (2003). Mobbing Emotional Abuse at Work. (O. C. Önertoy, Trans.) Sistem Publishing., 20-23.

Einarsen, S. (1999). The Nature and Causes of Bullying at Work. International Journal of Manpower, 20 (1/2), 16-27. 
Eğin, A. (2015). Work Stress and Burnout in Working Life. Beykent University Institute of Social Sciences, İstanbul, 8-44.

Gök, S. (2009). An Important Problem in Working Life Organizational Stress. Journal of Marmara University Faculty of Economics and Administrative Sciences, 430-435.

Greenhaus, J. H., Beutell, N. J. (1985). Sources of Conflict between Work and Family Roles. Academy of Management Review, 77-80.

Güçlü, N. (2001). Stress Management. Gazi University, Journal of Gazi Faculty of Education, 21(1), 92-100.

Hofstede, G. (2011). Dimensionalizing cultures: the hofstede model in context. International Association for Cross - Culturel Psychology, 21-22.

Houdmont, J., Leka, S. (2010). An Introduction to Occupational Health Psychology. Occupational Health Psychology, 1-31.

ILO (1998). International Labour Organization. 15.03. 2019 tarihinde www.ilo.org adresinden alındı.

Kirk, W. J. (2017). Workplace Bullying: Proven Methodologies to Mitigate the Issue within the Government Contracting Workplace Environment. Florida, 7-21.

Korkut, A. E. (2014). Psychosocial Risk Factors and A Study in Construction Sector. Ministry of Labor and Social Security, Ankara, 3-5.

Leka, S., Cox, T. (2008). Towards the Development of a European Framework for Psychosocial Risk Management at the Workplace. Nottingham: I-WHO Publications, 1.

Leymannn, H. (1990). Mobbing and Psychological Terror at Workplaces. Violence and Victims, 119-126.

Leymann, H. and Gustafsson, A. (1996). Mobbing at Work and the Development of Post-Traumatic Stress Disorders. European Journal of Work and Organizational Psychology, 5 (2), 251-275.

Newman, J. E., Beehr, T. A. (1984). Personal and Organizational Strategies for Handling Job Stress: A Review of Research and Opinion. IEEE Engineering Management Review, 58.

Özağaç, G. S. (2013). Psychosocial Health in Workplaces: The Case of Tekirdag Province. Namık Kemal University. Health Sciences Institute, Master Thesis, 14-15.

Rantanen, J. (1999). Research Challenges Arising From Changes in Worklife. Scand J Work Environ Health, $478-479$.

Richards, J. (2003). Management Of Workplace Violence Victims. ILO/ICN/WHO/PSI Joint Programme on Workplace Violence in the Health Sector, 20-22.

Şahan, C. (2016). Adaptation of the Copenhagen Psychosocial Risk Assessment Scale to Turkish. Dokuz Eylül University Institute of Health Sciences, İzmir, 4.

Şenyiğit, G. (2004). Stress in working life. Journal of Productivity (3), 103.

Tinaz, P. (2006). Psychological Abuse at Work (Mobbing). Work and Society, 25-27.

Türetgen, I. Ö., Berk, Ö. S., Başbuğ, G., \& Ünsal, P. (2012). The development of the Job Stressor Appraisal Scale as part of the Job Stress Battery. European Journal of Psychological Assessment, 147-153.

Uslu, V. (2014). The Relationship Between Occupational Safety Performance and Occupational Safety Culture in Enterprises: A Research in Eskişehir Metal Industry. Eskişehir Osmangazi University, 3839.

Ültanır, G. (2003). The Relationship Between Education and Culture-The Anxiety of Which Dimensions of Culture in Education to Transfer to Young Generations. Gazi University, Gazi Education Faculty Journal, 23(3), 291-309.

Vatansever, Ç. (2014). A New Dimension in Risk Assessment: Psychosocial Hazards and Risks. Work and Society, 117-138. 
WHO. (1946). World Health Organization. 22.03.2019 tarihinde www.who.int adresinden alındı.

Wolinska, J., Rakowska, A. (2014). Organizational Culture And Its Role in Business. The Example Of Polish Culture, Management Knowledge and Learning International Conference, 1089-1093.

Yıldırım, A., Şimşek, H. (2005). Qualitative research methods in the social sciences. Ankara: Seçkin, 366.

Yilmaz, H., Kaymaz, A. (2014). A Risk Factor: Mobbing (Psychological Abuse in the Workplace). Public Internal Auditors Association (KIDDER), 75.

Yumuşak, S. (2008). A Field Study on Investigation of Factors Affecting Employee Efficiency. Süleyman Demirel University Journal of Economics and Administrative Sciences, 13, 241-247.

Zapf, D. (1999). Organizational, Work Group Related and Personal Causes of Mobbing/Bullying at Work. International Journal of Manpower, 20 (1/2), 70-85. 